\title{
Identifying design guidelines for online information resources: a study of expectant and new mothers
}

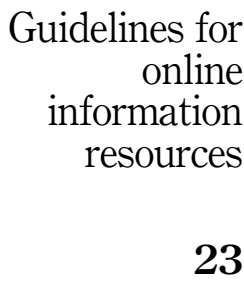

Received 6 April 2020 Revised 18 March 2021 Accepted 27 April 2021

\begin{abstract}
Purpose - The purpose of this article is to identify design guidelines for online resources based on the subjective assessment criteria used by individuals to assess and process information resources. This method of creating design guidelines targeted at precise user groups has the potential to aid designers and developers to create more user-centred information resources.

Design/methodology/approach - The authors gathered data using a prospective longitudinal study investigating the information behaviour of expectant and new mothers. Women were asked to report on their information-seeking activities in a series of semi-structured interviews covering pregnancy and early motherhood. Findings - This research identified 15 assessment criteria that were utilised by women to assess and process information resources. The most popular resource criteria amongst participants were credibility and convenience, while completeness and relevance were the most popular information content criteria. The authors found that assessment criteria were not considered in isolation, with criteria such as formatting and search engine ranking impacting on participants' perception of other criteria.

Practical implications - This research demonstrates the potential of linking a user groups subjective assessment criterion to design guidelines. The authors propose that these guidelines could be used to help design an online information resource. They could also be used to assess if an existing online resource met the needs of a user group. The methodology used in this study could be leveraged to create design guidelines for user groups. Originality/value - This research uses subjective assessment criteria as a means of understanding how expectant new mothers process information resources. People use subjective judgements when processing information resources, and this should be incorporated into the design of information resources. Analysing longitudinal data allowed the authors to build a rich picture of how participants evaluated and compared different information resources.
\end{abstract}

Keywords Information behaviour, Information processing, Information-seeking, Design guidelines, Longitudinal, Subjective assessment criteria, Information resources

Paper type Research paper

\section{Introduction}

The current era can be defined by ubiquitous access to information and the continuous expansion of network information resources (Xiong and Zuo, 2019). Researchers have raised concerns over the quality of information online and the lack of general quality standards for online information (Metzger, 2007; Savolainen, 2011; Ghasemaghaei and Hassanein, 2015). However, quality is a highly subjective concept which can make it difficult for researchers and web designers to measure it objectively (Arazy and Kopak, 2011).

Users' subjective perceptions when seeking information can determine their subsequent actions (Zhang et al., 2019). For example, researchers have found the effort it requires to process information influences a user's perception of the content (Meppelink et al., 2016). As

(C) Carolanne Mahony, Ciara Heavin and David Sammon. Published by Emerald Publishing Limited. This article is published under the Creative Commons Attribution (CC BY 4.0) licence. Anyone may reproduce, distribute, translate and create derivative works of this article (for both commercial and noncommercial purposes), subject to full attribution to the original publication and authors. The full terms of this licence may be seen at http://creativecommons.org/licences/by/4.0/legalcode

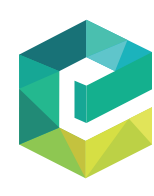

Information Technology \& People Vol. 35 No. 8, 2022 Emerald Publishing Limited 0959-3845 DOI 10.1108/ITP-04-2020-0180 
ITP

35,8

information-seekers use subjective measures when assessing online resources, this should be reflected in the design of information resources (Ho et al., 2013).

This unique study uses concepts from the information behaviour domain to produce design guidelines for online information resources. Specifically, this research analyses how individuals process existing information resources using subjective assessment criteria. As information-seekers subjectively assess information resources and the information they contain, this should be reflected in the design of information resources (Ho et al., 2013).

The importance of useful design guidelines is often overlooked; this may be due to designers choosing to follow trends or their intuition (Beukes et al., 2016). Guidelines should not be a rigid set of standards; however, they do need to be based on more than just opinion (Shneiderman, 2006). Instead, guidelines should come in the form of prescriptive recommendations (Shneiderman, 2006). These recommendations can be used to provoke discussion amongst relevant stakeholders allowing them to work through their conflicting preferences and interests (Yetim, 2006).

Information behaviour and information systems (ISs) are conjunct disciplines with shared research interests (Ellis et al., 1999). Research suggests that the study of information behaviour could provide useful insights for IS researchers and developers (Hwang et al., 2010). Information behaviour research changes the focus of questions from systems use to information needs and task behaviours (Wilson, 2000).

Context plays a critical role in continued systems use (Kari et al., 2020). To create supports that meet the needs of different groups, it is essential to undertake studies in different contexts; for example, different cultures, countries and covering different health conditions (Sanders et al., 2020). The context of this study is expectant and new mothers, whom have been identified as a rich context in which to study information-seeking (Mckenzie, 2004). The term "expectant mothers" refers to women in the prenatal period. For the purpose of this study, new mothers refer to the postpartum period from zero to twelve months. Expectant and new mothers are active information-seekers who search for information for themselves and their families (Bernhardt and Felter, 2004; O'connor and Madge, 2004). Existing research indicates that this cohort often consults a variety of information resources before making decisions (Sillence et al., 2007a). Motherhood is a significant life event that can impact numerous areas of a woman's life, including her identify, her priorities and her life goals (Ruthven et al., 2018).

The main objective of this research is, therefore, to produce design guidelines for online resources for expectant and new mothers. These design guidelines are based on the subjective assessment criteria used by the expectant and new mothers. The next section is the literature review; this section provides insight into information behaviour and information processing, how the initial assessment criteria were identified from the literature and the context of the study. Section 3 discusses the longitudinal research method, data collection and analysis. The findings of the study are covered in Section 4. In this section, commentary is provided on how the study participants evaluated different information resources. Section 5 takes the findings and presents design guidelines for online information resources. Finally, Section 6 concludes with a discussion of the contributions and limitations of the study, and by highlighting potential areas for future research.

\section{Literature review}

\subsection{Information behaviour and information processing}

Information behaviour and IS are conjunct disciplines with shared research interests (Ellis et al., 1999). Both disciplines focus on research questions concerned with the interaction of people, information and technology (c.f. Sawyer and Huang, 2007). Information behaviour "focuses on people's information needs; on how they seek, manage, give, and use information, both purposefully and passively" (Fisher and Julien, 2009, p. 1). Research has suggested that the study of information behaviour could provide useful insights for IS researchers and 
developers (Hwang et al., 2010). Information behaviour research changes the focus of questions from systems use to information needs and task behaviours (Wilson, 2000).

Previously IS studies have identified the importance of context for IS success (e.g. Kim et al., 2015; Jeyaraj, 2020). However, the importance of individual success measures is not consistent, with different measures being relevant depending on the system, user or environment (Delone and McLean, 2003). Studies have also shown that context plays a critical role in continued systems use (Kari et al., 2020). As illustrated in Figure 1, context is also central to information behaviour studies. Researchers have long argued that innovative and useful contributions can only be produced through understanding the context of information users (Wilson, 1981). For example, Sarkar and Sarkar (2019) found that young adults evaluate mobile apps differently depending on whether they consider the app to be hedonistic or utilitarian. Alternative terms used for context within information behaviour include setting, environment, information-world and information-ground (Courtright, 2007). The context for this study is expectant and new mothers.

Reviews of information behaviour research have highlighted that studies have tended to focus on information needs and information seeking, with relatively few researchers investigating how information is processed and used (Case and O'Connor, 2016; Pluye et al., 2019). As discussed by Mahony et al. (2021), the terminology in the area of information processing and use is inconsistent with multiple concepts having overlapping definitions (i.e. information processing, information use and information utilisation). For example, in Wilson's (1997) revised model of general information behaviour, he defines information processing in terms of information being incorporated into the seekers knowledge, values or beliefs, and information use as changes to knowledge, behaviour, values or beliefs. Wilson later combines these definitions under the single concept of information use behaviour (Wilson, 2000). Hughes (2006) definition of information use was very broad, encasing all aspects of information behaviour: "information needs and context, their information seeking and use of information and their learning outcomes."

Mahony et al. (2016) defines information processing and information use as two distinct phases; with information processing defined as evaluating and comparing information resources and information use defined as the outcomes of the information behaviour process. Zhang et al. (2020) adopted a similar perspective when they examined the factors that impact knowledge adoption using the dual-process theory of ELM (Elaboration Likelihood Model)/ KAM (Knowledge Adoption Model) derived from social psychology.

Another perspective found in the literature is to examine information processing in terms of cognitive capacity and mental effort (Park, 2013). Recent research has explored factors that impact on information-seekers ability to process information, and the potential negative impacts such as information overload, avoidance and anxiety (Blankenburg Holm et al., 2020; Lee et al., 2020; Soroya et al., 2021).

For the purpose of this study, we define information processing as having two stages, evaluation and comparison (Mahony et al., 2016); this is illustrated in Figure 2. Information

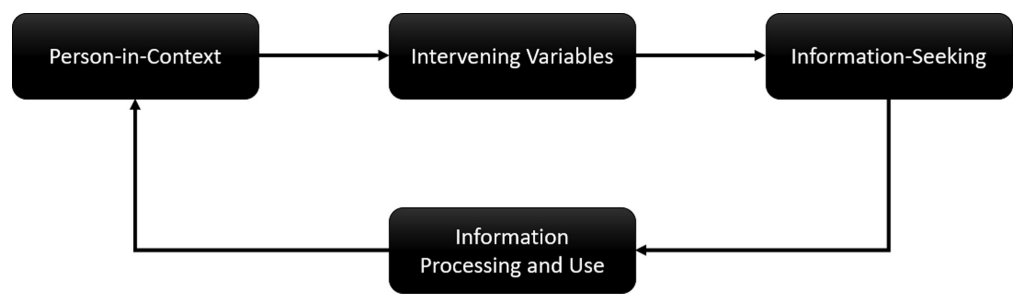

Figure 1. Information behaviour process

\section{Guidelines for online information resources}

Source(s): Adapted from: (Wilson, 1999) 
ITP

35,8

26

processing is a crucial part of the feedback loop, ensuring that information needs are satisfied (Wilson, 1999). Evaluation is where information-seekers determine the quality of information resources using assessment criteria (Ellis et al., 1993; Foster, 2004; Watson, 2014). The growth of misinformation and disinformation online makes understanding how individuals evaluate information particularly relevant (c.f. Leeder, 2019).

During the comparison stage of information processing, information-seekers may compare information from multiple information resources as a method of verification (Ellis et al., 1993; Watson, 2014). Information-seekers may also choose to combine the information into one "information product" (Foster, 2004; Watson, 2014). This stage can involve both external information resources and internal cues, such as relevant prior beliefs or past experiences (Wood et al., 1985).

Information processing is subjective and occurs within the mind of the information-seeker (Wilson, 1997). This can make information processing challenging for researchers to analyse (Wilson, 1997; Bawden and Robinson, 2012). However, through understanding the subjective assessment criteria utilised by information-seekers to make quality judgements, it may be possible to produce information resources that better meet their requirements (Mahony et al., 2016). The next section discusses the subjective assessment criteria.

\subsection{Subjective assessment criteria (SAC)}

Individuals judge quality based on subjective criteria, and these can evolve over-time (c.f. Hilligoss and Rieh, 2008; Lee et al., 2019a). To provide insight into this process, this study developed a list of subjective assessment criteria (SAC) based on information quality (IQ) and systems quality (SQ) concepts. Research has identified IQ and SQ as two of the main factors in determining end-user satisfaction (Delone and McLean, 1992; Delone and Mclean, 2003; Wang, 2008). When searching for information, the quality and quantity of information that users find can have a significant impact on their decision-making ability (Deng et al., 2017).

To create the list of SAC, a review of information behaviour and IS literature was undertaken following the concept centric matrix approach (c.f. Webster and Watson, 2002). We divided the SAC concepts into two tables. Table 1 represents information resource concepts; this is closely linked to SQ. Table 2 represents information content concepts; this is linked to IQ.

Information-seekers can search, process and combine multiple sources of information. It is, therefore, essential to be able to compare how they select and evaluate different information resources (Sbaffi and Rowley, 2017). As such, we use the term information resource instead of information systems in Table 1 to allow us to broaden our scope and include more than just systems but also any source of information, including print and personal.

We identified the SAC concepts by reviewing seminal and highly cited articles on IQ and SQ in ISs (e.g. Delone and Mclean, 1992; Strong et al., 1997). The review also targeted information behaviour research (e.g. Rieh, 2002; Sillence et al., 2007b), including how different

Figure 2.

Components of information processing



Source(s): Adapted from (Mahony et al., 2016) 


\begin{tabular}{|c|c|c|c|c|c|c|c|c|c|}
\hline (оzоz ‘'е дә биечz) & & $\times$ & & & & & & & \\
\hline (6LOz 'p p jo uns) & $\times$ & $\times$ & & $\times$ & & $\times$ & & $\times$ & $\times$ \\
\hline 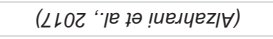 & $\times$ & & $\times$ & $\times$ & & & & & $\times$ \\
\hline (LเOZ 'ןе ғә Бие!7) & $\times$ & & & & & & & & $\times$ \\
\hline (9LOZ 'ןе дә оеэ) & & & & $\times$ & & & $\times$ & & $\times$ \\
\hline 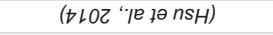 & & $\times$ & & & & & $\times$ & $\times$ & $\times$ \\
\hline (عเо乙 'ןе ұә Биәчz) & $\times$ & & & $\times$ & & & & $\times$ & $\times$ \\
\hline 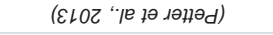 & & & $\times$ & & & & $\times$ & & $\times$ \\
\hline 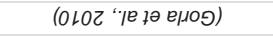 & & & $\times$ & $\times$ & $\times$ & $\times$ & $\times$ & & $\times$ \\
\hline (6002 'uoss.e7) & & $\times$ & & $\times$ & & & & & \\
\hline 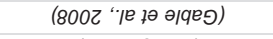 & $\times$ & & $\times$ & $\times$ & $\times$ & $\times$ & & & $\times$ \\
\hline (800z ‘'ичем) & & & & & & & & $\times$ & $\times$ \\
\hline (800z '”е łә Бипәчว) & & $\times$ & & & & $\times$ & & & \\
\hline 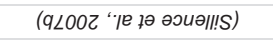 & $\times$ & $\times$ & & $\times$ & & & & & \\
\hline (sooz 'ppo $\perp$ pue mox!M) & $\times$ & & $\times$ & $\times$ & $\times$ & & $\times$ & & \\
\hline (cooz “’e дә бие人) & $\times$ & & & & & $\times$ & & $\times$ & $\times$ \\
\hline 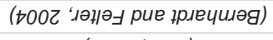 & $x$ & $\times$ & & & & & & & \\
\hline (z00z ‘yə!') & & $\times$ & & $\times$ & & $\times$ & & & \\
\hline 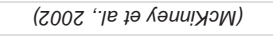 & $\times$ & & & & & $\times$ & & & $\times$ \\
\hline 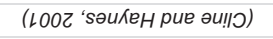 & & $\times$ & & $\times$ & & & & & $\times$ \\
\hline (L66L'”e tә Биолs) & $\times$ & $\times$ & & & & & $\times$ & $\times$ & \\
\hline (Z66ь ‘иеә7эш рие әиорәа) & $\times$ & & $\times$ & & $\times$ & $\times$ & $\times$ & & $\times$ \\
\hline 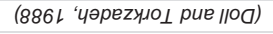 & & & & $\times$ & & & & & $\times$ \\
\hline (E86L 'uosıeәd pue КәІ!eg) & $\times$ & & $x$ & $\times$ & $\times$ & $\times$ & $\times$ & $\times$ & \\
\hline $\begin{array}{l}\text { 듬 } \\
\text { 을 } \\
\text { 돈 }\end{array}$ & 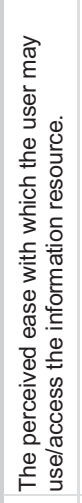 &  & 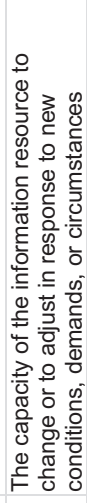 & 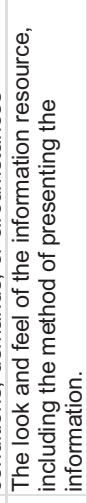 & 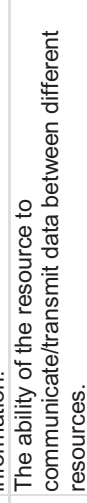 & 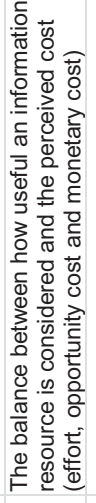 & 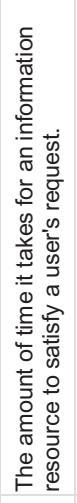 & 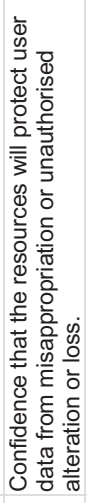 & 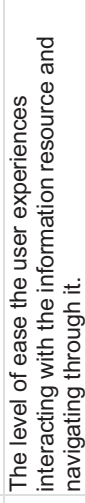 \\
\hline $\begin{array}{l}\frac{0}{0} \\
\text { ঠे }\end{array}$ & 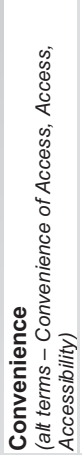 & 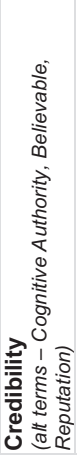 & $\frac{7}{\overline{0}}$ & 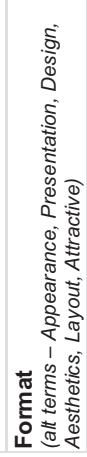 & 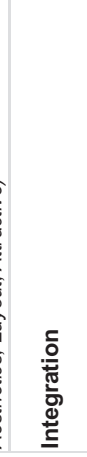 & 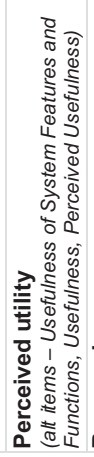 & 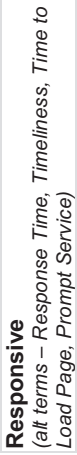 & 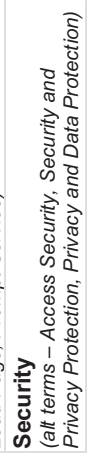 & 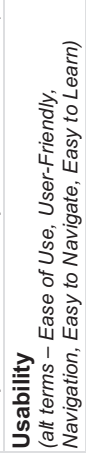 \\
\hline
\end{tabular}

Guidelines for online information resources
Table 1.

Information resource subjective assessment 
ITP

35,8

28

\begin{tabular}{|c|c|c|c|c|c|c|c|c|c|}
\hline (оzоz 'юе дә биечz) & & $\times$ & & $\times$ & & $\times$ & & $\times$ & \\
\hline (6Loz ' & $\times$ & $\times$ & & $\times$ & $\times$ & $\times$ & $\times$ & $\times$ & \\
\hline  & $\times$ & $\times$ & & & $\times$ & & & $\times$ & \\
\hline 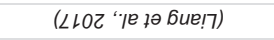 & $\times$ & $\times$ & & $\times$ & $\times$ & $\times$ & $\times$ & & \\
\hline (SLOZ '/e fə оеפ) & $\times$ & $\times$ & & $\times$ & & & & $\times$ & \\
\hline 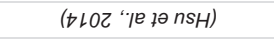 & & $\times$ & & $\times$ & & & & & $\times$ \\
\hline 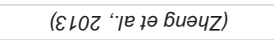 & & $\times$ & & $\times$ & $\times$ & $\times$ & & & $\times$ \\
\hline 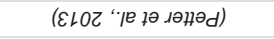 & $\times$ & $\times$ & $\times$ & $\times$ & $\times$ & & & $\times$ & \\
\hline (оцог “رе ғә еноэ) & $\times$ & $\times$ & $\times$ & & $\times$ & & & $\times$ & \\
\hline (6002 ‘uossıe7) & & & & $\times$ & $\times$ & & $\times$ & & \\
\hline 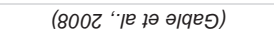 & $\times$ & & $\times$ & $\times$ & $\times$ & & & $\times$ & \\
\hline (800z ‘6ием) & $\times$ & $\times$ & & $\times$ & & & & & $\times$ \\
\hline (800z '”ן дә Бипәчว) & $\times$ & & & $\times$ & & & & $\times$ & \\
\hline  & & & & & $\times$ & $\times$ & & $\times$ & \\
\hline (sooz 'ppo $\perp$ pue шох!M) & $\times$ & $\times$ & & $\times$ & & & & & \\
\hline (s00z '”е ұә Бие人) & $\times$ & & & $\times$ & $\times$ & & $\times$ & $\times$ & $\times$ \\
\hline (†०о乙 ' & & $\times$ & & & $\times$ & $\times$ & $\times$ & & $\times$ \\
\hline (z૦૦z '4ә!) & $\times$ & & & $\times$ & $\times$ & & & & $\times$ \\
\hline 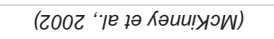 & & $\times$ & & $\times$ & & & & $\times$ & $\times$ \\
\hline ( (০০০z ‘sәuКен рие әи!Ј) & $\times$ & & & $\times$ & $\times$ & & $\times$ & & \\
\hline 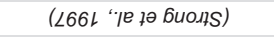 & $\times$ & $\times$ & $\times$ & $\times$ & $\times$ & $\times$ & & $\times$ & \\
\hline (Z66ь ‘иеә7эW рие әиоюәа) & $\times$ & $\times$ & $\times$ & $\times$ & $\times$ & $\times$ & & $\times$ & $\times$ \\
\hline 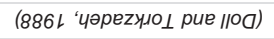 & & $\times$ & & $\times$ & & & & $\times$ & \\
\hline (E86L ‘uosıеәd pиe КәІ!еg) & $\times$ & $\times$ & $\times$ & $\times$ & & & & $\times$ & $\times$ \\
\hline 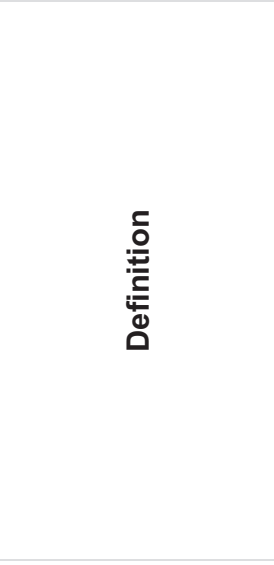 & 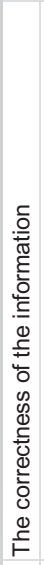 & 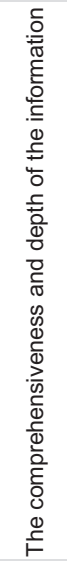 & 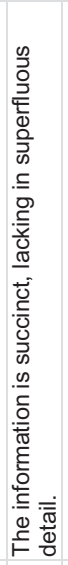 & 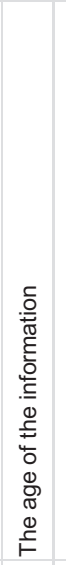 & 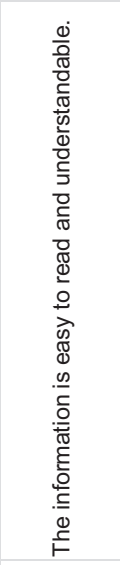 & 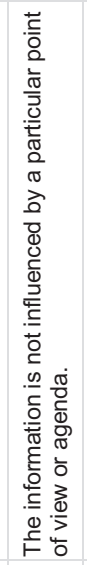 & 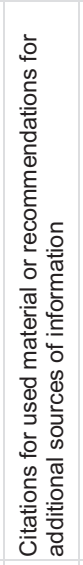 & 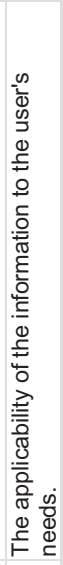 & 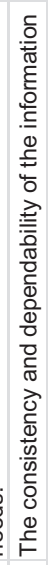 \\
\hline $\begin{array}{l}0 \\
\text { O웅 }\end{array}$ & 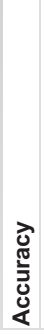 & 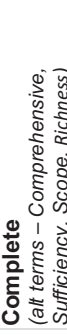 & 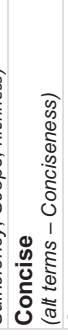 & 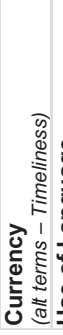 & 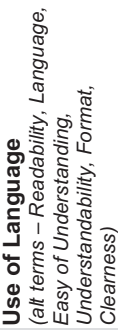 & 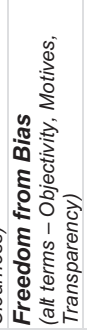 & 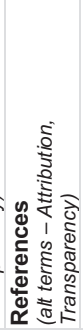 &  & 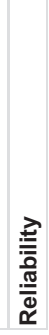 \\
\hline
\end{tabular}

Table 2.

Information content subjective assessment criteria 
information resources were processed (e.g. Cheung et al., 2008; Zhang et al., 2020). Considering the context of the study, we were particularly interested in concepts that emerged from studies involving expectant and new mothers (e.g. Bernhardt and Felter, 2004; Larsson, 2009). We observed the cohort's tendency to be actively engaged in health information-seeking.

The phrase "alt terms" can be found several times under the definitions in both Tables 1 and 2. In this context, "alt terms" is used to highlight alternative words or phrases found in the literature used to explain the same concept. For example, timeliness can be used as an alternative term for the currency of data. Another example is cognitive authority, which is down as an alternative term for credibility. Cognitive authority is not precisely the same as credibility, but it is closely related (Rieh and Danielson, 2007). Wilson's (1983) theory proposes that people assign cognitive authority to information resources based on how much they believe the information resource knows about a topic. For example, an information-seeker might consider their friend a good source of information when buying a new computer but not when seeking medical advice. Rieh (2002) operationalises this in terms of how much the user can trust the information provided by the information resource.

To create a website that meets the needs of users, it is essential to understand their requirements and how they evaluate different resources. However, designers can have a preference for using their instincts or following fashions instead of working with end-users (Beukes et al., 2016). Changes to the design of online information resources can have unintended consequences. For example, changes made to WebMD forums negatively impacted their popularity (Introne et al., 2019). Design guidelines can be advantageous during web design projects. Although guidelines are not comprehensive academic theory, they can provide a useful set of recommendations (Shneiderman, 2006). They can be valuable to stakeholders such as researchers, designers, managers and usability specialists (Beukes et al., 2016). Input from users is essential to ensure that guidelines reflect user needs and preferences (Zaphiris et al., 2009).

\subsection{Context of study: expectant and new mothers}

The context for this study is expectant and new mothers. Studies have noted differences between genders when researching how people search for and evaluate health information. Ek (2015) indicated that "being female is a strong predictor of being more proactive and engaged in seeking, gaining and discussing health-related issues" (p. 741). The impact that pregnancy and motherhood has on a woman's sense of identity is considered one of the primary drivers of information-seeking (Montesi, 2017). Becoming a mother can bring major changes to a woman's life, from practical day to day changes to alterations in priorities and life goals (Ruthven et al., 2018). As a result, pregnancy and parenting have been identified as a rich context in which to study information-seeking (Mckenzie, 2004).

Expectant mothers fall into a unique category between being well and being ill (Cohen and Raymond, 2011). Mothers are usually more active information-seekers than fathers (Plantin and Daneback, 2009), with information-seeking often increasing during pregnancy (Prescott and Mackie, 2017). Although not all expectant mothers experience ailments as a result of their pregnancy, they must continuously make health decisions that can impact themselves and their unborn child (Wennberg et al., 2013). Information-seeking is often associated with uncertainty, where the seeker feels a lack of confidence in their state of knowledge (Beldad et al., 2011). Due to the degree of change that occurs during pregnancy and early motherhood, it is perhaps unsurprising that information-seeking can increase during this period.

Studies show that expectant and new mothers search for information on a variety of topics during pregnancy and early motherhood. Topics include both general and health information-seeking. Examples of search topics include:

(1) Antenatal complications (Slomian et al., 2017);
Guidelines for online information resources 
ITP

35,8

30

(2) Labour (Gao et al., 2013; Montesi, 2017);

(3) Health conditions (Slomian et al., 2017; Naveh and Bronstein, 2019);

(4) Diet and exercise (Das and Sarkar, 2014; Yadav et al., 2019);

(5) Parenting strategies (Porter and Ispa, 2013; Lee, 2018);

(6) Products (Lagan et al., 2010; Fourney et al., 2015);

(7) Childcare and education (Brady and Guerin, 2010).

Research has suggested that increased health information-seeking during pregnancy can lead to better self-care abilities, increased knowledge and potentially better pregnancy outcomes (Shieh et al., 2009). Searching for information online and interacting with online communities can provide mothers with a sense of empowerment, social support and relief from the isolation which can occur during early motherhood (Pettigrew et al., 2016; Madge and O'connor, 2006; Gibson and Hanson, 2013).

\section{Research methodology}

This study was undertaken from a social constructivist perspective. Social constructivism espouses that ISs are embedded in social contexts (Orlikowski and Baroudi, 1991). They influence and are influenced by aspects of their environment, for example, their user groups (Latour, 1990). This perspective fits with the study's focus on people and technology in context.

This study employed a prospective longitudinal case study. Case studies are a wellestablished research method within IS research (Benbasat et al., 1987; Lee, 1989; Walsham, 1995; Klein and Myers, 1999; Ngwenyama and Nielsen, 2014). In contrast to a snapshot view, in a longitudinal study, the researcher develops an in-depth understanding of a phenomenon and how it evolves over time (Lee et al., 2019b). As context is vital for IS success (Kari et al., 2020), we wanted to gain an in-depth understanding of the context of the users in this study to facilitate the creation of the design guidelines. Specifically, our aim was to understand how the participants processed information resources across the different stages of pregnancy and early motherhood.

Figure 3 provides a high-level breakdown of the research design. Participants were recruited in the second trimester of pregnancy. We selected the second trimester for practical reasons because many women are nervous to talk about their pregnancies before this point. We used a form of snowball sampling to recruit participants (Rodríguez-Ardura and Meseguer-Artola, 2019), notices were placed on social media groups and in a newsletter that targeted pregnant women. The research design included seven waves of data collection with each study participant, Figure 3 . The waves were scheduled at three-month intervals to cover the period of pregnancy and early motherhood.

Figure 3.

Research design

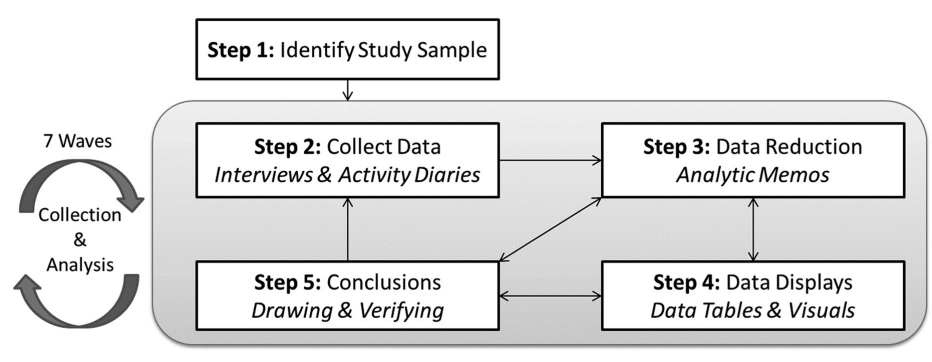


The study was longitudinal; this allowed us to conduct cycles of data collection and analysis. The data were analysed using a mix of theoretical and inductive thematic analysis (Braun and Clarke, 2006). The data were first analysed using a theoretical thematic analysis where the data were analysed using the SAC discussed in Section 2.2. Next, we recoded the data using an inductive approach. We completed this process to ensure any criteria that had not been identified from the literature review were identified and to identify and code contextual factors.

At the end of the data collection, once all the data had been collected and analysed, we used the coded data to produce the design guidelines. The next sections provide more detail on the process.

\subsection{Data collection}

The critical factor in deciding the length of the data collection period per participant was the research objective, which specifies the analysis of subjective criteria used by expectant and new mothers. For practical reasons, we decided to recruit women in the second trimester. As stated previously, women can be nervous to talk about their pregnancies before this point. To observe the information behaviour of new mothers, we decided to collect data for a minimum of 12 months after childbirth. There is no universally accepted definition for the term "new mother" (Davis, 2015); however, researchers in the medical field have studied maternal role attainment (MRA). MRA examines the experiences of mothers in the first year after childbirth (Barkin et al., 2010). We used the MRA definition as the definition of "new mother" in the context of this study, and this helped to determine the length of data collection. Combining this with the expectant mother phase, the length of data collection per participant was approximately eighteen months.

Data collection was completed over seven "waves" divided throughout the study, Figure 4. Twelve expectant mothers originally signed up for the study; however, due to attrition, only the data from nine were included in the final analysis. Unfortunately, attrition is a common problem with prospective longitudinal studies (Ployhart and Vandenberg, 2010). Two participants exited after their first interview. Another participant exited after her third interview because she moved to a different county. Data from these three participants were not included in the final study because we decided that four waves would be the minimum threshold for inclusion. Four waves gave us sufficient data to contrast the participants' prenatal and post-natal information resource assessments. As a result, data from nine participants were included in the final data analysis. Seven of those participants completed the full seven waves, one participant completed four and one completed five, see Figure 4.

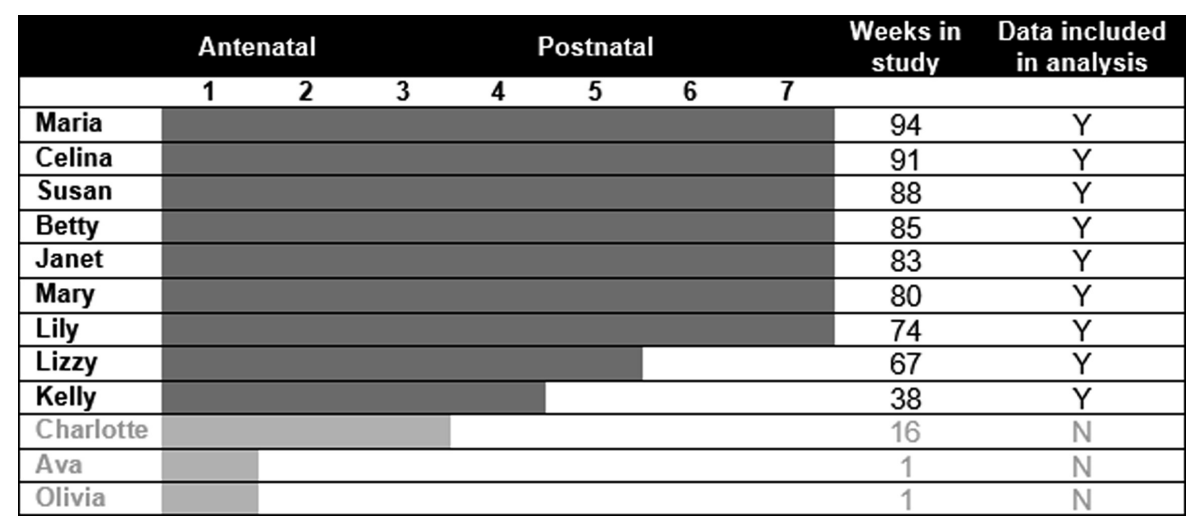

Guidelines for online information resources 
ITP

35,8

32

Figure 5.

Sample activity diary
Data were collected using semi-structured interviews and activity diaries. In each interview, participants were asked to recount examples of information-seeking. During the interviews, participants were asked to narrate their perceptions of the different information resources accessed and rejected. Interviews are considered one of the most important qualitative research methods (Qu and Dumay, 2011). They are an efficient method of gathering rich, empirical data (Eisenhardt and Graebner, 2007). Semi-structured interviews in particular, allow the researcher to "delve deeply into social and personal matters" (DiCiccoBloom and Crabtree, 2006, p. 315), making them useful for studying the contextual elements of information behaviour.

During the interview process, the interviewer needs to show empathy for the interviewee (Myers and Newman, 2007). As this was a longitudinal study, which required a significant commitment from the participants, the need for empathy was particularly relevant. Interviews were undertaken at a time and location which suited the participant. This meant that interviews often occurred in the participants own home, sometimes late in the evening. Although we planned to schedule the interviews every three months, adjustments were accommodated due to illness or family commitments. These adjustments explain the differences in time that it took participants to complete the study, see Figure 4.

Interviewing does come with its challenges; some of the challenges faced during this study were discussed in previous articles, such as dealing with shy or disinterested interviewees (Myers and Newman, 2007). However, challenges that are not usually discussed is a researcher's fear when they watch an eight-month pregnant interviewee run up a slide because their toddler is refusing to come down. There is also a lack of advice on how interviewing somebody while they are getting their hair cut, in their kitchen, while their hairdresser keeps interrupting to ask questions.

The second method used to collect data was an activity diary. Interviews were the primary method of data collection, while the activities diaries were used as a way for participants to record their information-seeking between interviews. Diaries are a useful method of augmenting interviews by providing insight into participants' day-to-day behaviour and experiences (Corti, 1993). The activity diaries became less successful in the antenatal period as some participants forgot to fill them in between sessions. Figure 5 provides an example of an activity diary collected during the study.

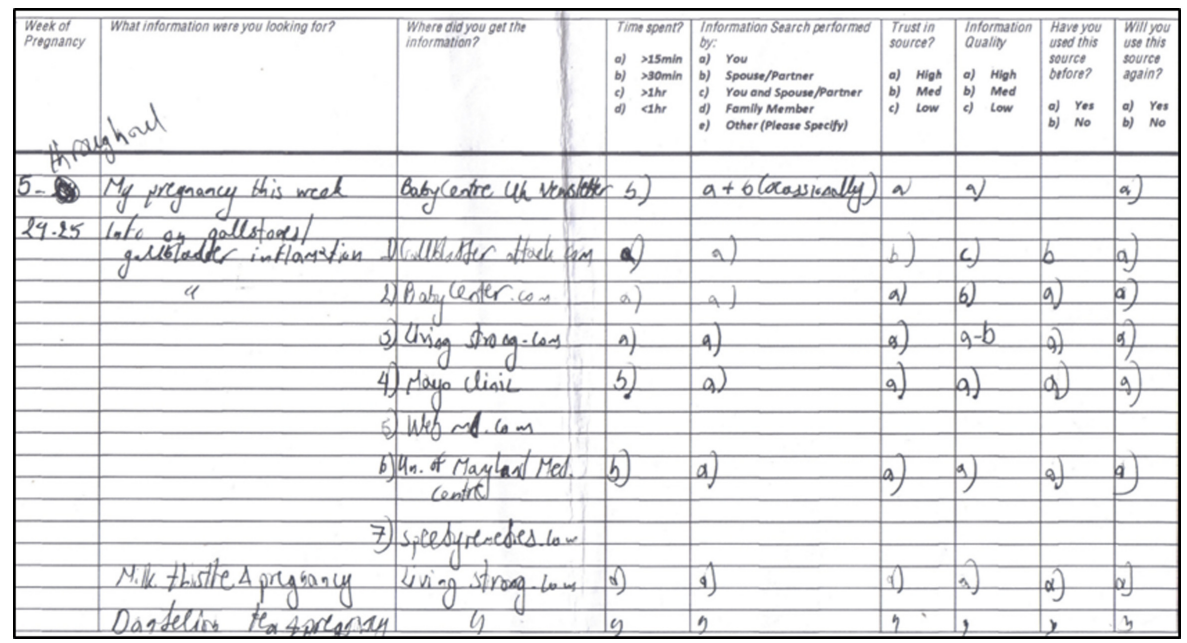




\subsection{Analysis}

Due to the length of a longitudinal study and the volume of data involved, the first step of data analysis was data reduction. Data reduction is a useful method for managing transcription data that would otherwise be spread over many different files (Miles et al., 2013). Throughout the study, 63 interviews were conducted, and 36 activity diaries were submitted. As discussed at the beginning of Section 3, coding and analysis was an iterative process. As each wave was completed, data were reduced, coded and analysed. This gave us time to create preliminary conclusions between waves and then to check interpretations with participants during the next interview. Semi-structured interviews are useful for this as they are designed to enable researchers to ask additional questions in order to gain further clarity about a topic of interest (Ikhalia et al., 2019). Figure 6 provides an example of an analytic memo from the study.

Data were analysed using thematic analysis (Athwal et al., 2019). We first used a deductive approach drawing on key concepts identified from the literature and used to form seed categories. The next step involved conducting an inductive approach to ascertain if any criteria had not been identified from the literature review and to identify and code contextual
Guidelines for online information resources

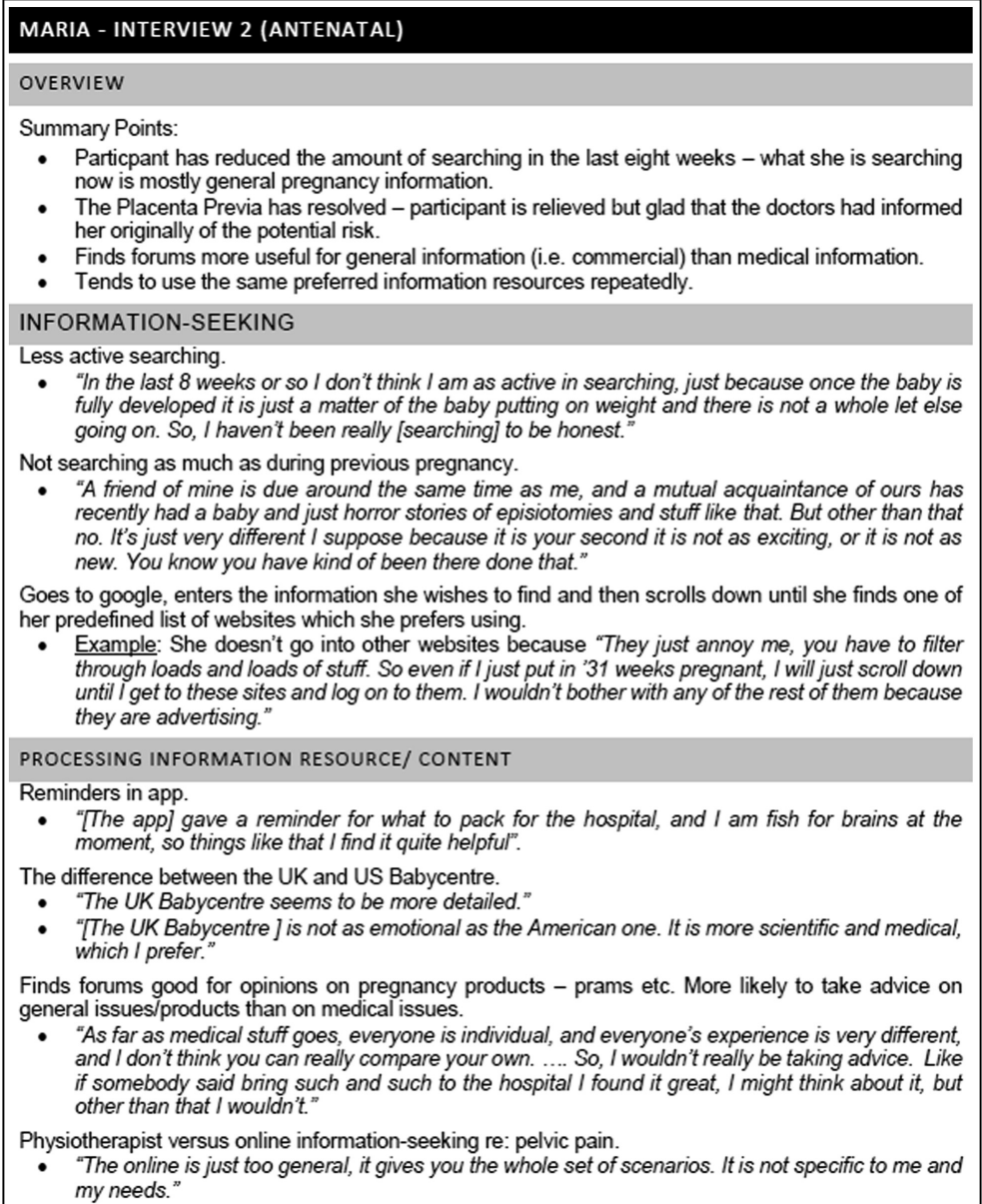

Figure 6.

Sample analytic memo 
ITP

35,8

34

factors. This hybrid approach was motivated by the desire to limit research bias and to provide the researchers with a better opportunity to identify the themes inherent in the data (Ikhalia et al., 2019). The seed codes used for the deductive analysis came from the SAC discussed in Section 2.2. For illustration, Table 3 displays quotes coded against the convenience code. Quotes were coded against the convenience code for seven out of the nine participants during the study.

Validation in qualitative research is fundamentally about assessing the degree to which the findings accurately represent the phenomena that the researcher is investigating (Hair, 2007). While quantitative research relies on statistical formulae to ensure validity (Straub et al., 2004), assessing validity in qualitative research is more diverse as it depends on the type of qualitative research undertaken (Hair, 2007).

Creswell and Miller (2000) proposed a framework to guide researchers in selecting validity procedures. The framework is divided into three sections: (1) lens of the researcher, (2) lens of study participant and (3) lens of people external to the study. Table 4 illustrates how this framework was applied to this study.

An example of one validity procedure used during the study was member checking, Table 4. This was done in two ways. During the interviews, participants were asked about analysis and interpretations gained from the previous interview. This was a continuous process that allowed us to validate their analysis. It also allowed further questions to be asked, when, on reflection, it was found that a topic had not been explored enough in a

\begin{tabular}{|c|c|}
\hline Participant & Quote \\
\hline Betty & $\begin{array}{l}\text { "I think because I'm already signed up to Facebook. If you go on the forums, you have to sign up } \\
\text { and answer questions from e-mails. It takes twenty minutes before you can even write } \\
\text { something. So, it would take too long if something was in your head and you wanted to say it" } \\
\text { "I always just use Google because it's easier, it's on my phone" }\end{array}$ \\
\hline Lizzy & $\begin{array}{l}\text { "I used to get books on everything, but it is just easier to go directly online, rather than to read a } \\
\text { whole book" }\end{array}$ \\
\hline Celina & $\begin{array}{l}\text { "It was handier to get the book than the laptop when the book was here. I just looked it up } \\
\text { quickly" } \\
\text { "No[the newsletter] just comes to my phone, and if I am on the toilet, I can read it. So, if I only had } \\
\text { it on my laptop and my box was full of newsletters, then it might be a nuisance, but it comes to } \\
\text { my phone, so it is very handy" } \\
\text { "Babycentre is so easy for me, and I know it, so I just go there" }\end{array}$ \\
\hline Susan & "I mean obviously, I look at the Internet quite a bit with things because it's just at your fingertips" \\
\hline Janet & $\begin{array}{l}\text { "I've two very small children, so actually getting out is not as easy as it was. I think that's } \\
\text { possibly one of the main reasons why I'm reverting to some of these forums, instead of attending } \\
\text { these groups, it is because I just can't get to them" }\end{array}$ \\
\hline Lily & $\begin{array}{l}\text { "I would buy my shopping online. I'm doing it now because I was sick at the start and now it's } \\
\text { just easier getting a big shop delivered because you don't have to lift all the stuff yourself" } \\
\text { "We have an account with Amazon, so it is just easier; you don't have to put in all your details } \\
\text { again" } \\
\text { "I don't hate computers; I mean it is just more of an effort to turn it on. It's not the first place I } \\
\text { think to go in terms of looking for information" }\end{array}$ \\
\hline Mary & $\begin{array}{l}\text { "Yeah, [the newsletter] comes and I always look at it. I find it actually very convenient" } \\
\text { "Since I went back to work which was before she turned one, I wasn't always reading the weekly } \\
\text { newsletters. ... because again, lack of time" } \\
\text { "For the health stuff, I would look a lot at the Internet because it's easier. It's just accessible } \\
\text { anytime" } \\
\text { "I suppose I would talk to people more about general information because it comes up in } \\
\text { conversation as well" }\end{array}$ \\
\hline
\end{tabular}

Table 3.

Quotes against the code convenience 


\begin{tabular}{|c|c|c|c|c|}
\hline \multirow{2}{*}{$\frac{\text { Lens }}{\text { Lens of the researcher }}$} & $\frac{\text { Procedure }}{\text { Trianoulation }}$ & \multicolumn{2}{|c|}{ Example from this study } & \multirow{4}{*}{$\begin{array}{r}\text { Guidelines for } \\
\text { online } \\
\text { information } \\
\text { resources }\end{array}$} \\
\hline & Triangulation & & $\begin{array}{l}\text { Use of both interviews and activity diaries } \\
\text { Use of cross-participant analysis }\end{array}$ & \\
\hline & $\begin{array}{l}\text { Disconfirming } \\
\text { evidence }\end{array}$ & (1) & $\begin{array}{l}\text { As this is a prospective longitudinal study, there } \\
\text { was room for the analysis to evolve and categories } \\
\text { to change through the different waves }\end{array}$ & \\
\hline \multirow{4}{*}{$\begin{array}{l}\text { Lens of study } \\
\text { participants }\end{array}$} & \multirow[t]{3}{*}{ Member checking } & \multirow{3}{*}{\multicolumn{2}{|c|}{$\begin{array}{l}\text { to change througn the different waves } \\
\text { (1) All study participants made themselves available }\end{array}$}} & \\
\hline & & & & \\
\hline & & & & \\
\hline & $\begin{array}{l}\text { Prolonged engagement } \\
\text { in the field }\end{array}$ & (1) & $\begin{array}{l}\text { As this is a longitudinal study, significant time was } \\
\text { spent with each participant }\end{array}$ & \\
\hline $\begin{array}{l}\text { Lens of the people } \\
\text { external to the study }\end{array}$ & Chain of Evidence & (1) & $\begin{array}{l}\text { Chains of evidence allow readers to understand how } \\
\text { conclusions were derived from the evidence }\end{array}$ & \\
\hline \multicolumn{4}{|c|}{ Source(s): Adapted from: (Creswell and Miller, 2000) } & Validity procedures \\
\hline
\end{tabular}

previous session. The second type of member checking was completed at the end of the study, once all the data were analysed and collated. Each participant was analysed as a single case, before being compared in cross-case. Three participants agreed to read their own full case analysis and to highlight any issues. Engaging in member checking provided us with sufficient evidence to satisfy saturation in the coding process.

\section{Findings}

\subsection{Information resource subjective assessment criteria (IRSAC)}

This section provides an overview of the IRSAC criteria used by expectant and new mothers; summarised in Table 5. The table includes all women whose data were included in the study. Also, present in the table, are all the IRSAC that were identified in Section 2.2. An X is used to indicate that there was at least one quote from that participant coded against that criterion. The criteria are organised top-down, with the criteria with the most quotes at the top. The participants are organised left to right, with participants who have quotes coded against the broadest range of criteria on the left.

Table 5 illustrates the fact that there were no quotes for the IRSAC criteria flexibility, integration and responsive. As a result, there will be no design guidelines based on these

\begin{tabular}{llllllllll}
\hline Code & Susan & Janet & Betty & Celina & Lily & Lizzy & Mary & Maria & Kelly \\
\hline Credibility & X & X & X & X & X & X & X & X & X \\
Convenience & X & X & X & X & X & X & X & & \\
Format & X & X & X & X & & X & X & \\
Rank on search list & X & X & X & & X & & & & \\
Usability & X & X & & & X & X & & & X \\
Perceived utility & X & & & X & & & & & \\
Security & X & & & & & & & & \\
Flexibility & & & & & & & & & \\
Integration & & & & & & & & &
\end{tabular}

Table 5. Summary of information resource SAC mentions by participant 
ITP

35,8

criteria in the next section. It is also clear from Table 5 that all participants were concerned with the credibility of the information resource, the provider of the information. Credibility is the only IRSAC with a quote from every participant against it, and it is the only IRSAC with a quote from Kelly. The next sections will discuss every criterion in more detail.

4.1.1 Credibility. Credibility was the Information Resource SAC criterion that was most frequently discussed across all the participants. It is defined in Section 2.2 as "the believability of the information resource". The analysis of participant data found that the believability of the information resources was judged primarily based on three factors:

(1) The professional qualifications and experience of the provider.

(2) The personal experience of the provider.

(3) The reputation of the provider gained through personal experience or brand awareness.

Professional qualifications were another sign of credibility for the study participants. Medical experts were a preferred information resource for medical tasks, particularly in cases of high uncertainty. Participants found medical experts even more credible when they had personal experience of a problem or situation. Betty was traditionally distrustful of medical professionals; she became more comfortable when she found a general practitioner (GP) who had children.

I don't normally trust the doctor. I trust someone who has been there and done that, whereas doctors are reading from textbooks and they are not always right.

All the participants trusted stories from other parents who had been through similar experiences. However, there was some concern about accessing personal stories through forums or blogs. This was because the identity of the authors could not be verified. Maria stated that she used Facebook Groups over forums because she felt the connection to a Facebook Profile adequately verified other users.

When you are on a forum you don't put in your real name; you have a nickname or a pseudonym whereas on Facebook they are using like Wendy English or Aideen Ni Ghallachoir. You feel it's okay that they are a real person.

We found evidence of participants combining information resources with different types of experiences. For example, when Mary got mastitis for the first time, she decided to gather information from "[her] midwife, [her] doctor, [her] sister and another two or three friends who had previously had it when they had babies in the past".

Janet highlighted the importance of an eHealth information resource projecting a professional feel, particularly when a parent is looking for information concerning the health of their child. However, Janet also found that she was more forgiving of formatting errors for well-known brands than for unknown sites. This demonstrated that one way for an online resource to appear more credible is to be affiliated with an organisation known to the target audience.

It was observed that credibility was context-specific and changed over time. For example, during the antenatal period, Lizzy referred to her sister as the person she most trusted. Her sister is a midwife and a mother. Lizzy used to ask her sister to verify information and advice that she had received from her GP. In the postnatal period, Lizzy and her sister disagreed over Lizzy's decision to do extended breastfeeding and baby-led weaning. Lizzy then described her sister as "just another medical point of view".

Medical experts were a preferred information resource for medical tasks, particularly in cases of high uncertainty. However, many of the participants did not judge them as credible when it came to parenting advice. 
4.1.2 Convenience. Convenience is defined in Section 2.2 as the "perceived ease with which the user may use/access the information resource." A review of the data found that online information resources were often considered convenient because of their ability to access information at any time, in a range of locations. However, there were also features of individual online information resources which made them less convenient, for example, the data entry requirements for an individual site. For Lizzy, convenience was the ability to find right information at the right time. She commented on how she "used to get books on everything, but it is just easier to go directly online, rather than to read a whole book."

When Betty was asked why she joined a Mother and Baby group on Facebook instead of on a forum, it was all down to convenience.

If you go on the forums you have to sign up and answer questions from e-mails. It takes twenty minutes before you can even write something. So, it would take too long if something was in your head and you wanted to say it.

Lily commented on the convenience of online shopping because you did not need to leave the house, and they delivered your orders. She preferred to order on Amazon because she had an account with them, so she did not have to retype her information; all the details were already saved.

4.1.3 Format. Format is defined in Section 2.2 as "the look and feel of the information resource, including the method of presenting the information." This is one criterion that can influence a user's perception of the other criteria. Poor formatting was shown to influence a user's perception of online information resource credibility. Betty commented that she and her husband "went for the doctor kind of sites; they looked more professional and seemed more accurate."

The format of a website was essential for Lizzy. She discussed how she would move on from a website based on its design.

It might be a bit judgemental, but it also depends on what the site looks like as well, how it is formatted, and if it is clean looking. Do you know? If it is very messy looking, I will just move on.

Janet noted the interplay between format and credibility. Mainly, when a website was associated with a well-known brand, it was easier to overlook formatting issues, but when she did not recognise the brand, she became more acutely aware of any issues.

4.1.4 Usability. Usability is defined in Section 2.2 as "the level of ease the user experiences interacting with the information resource and navigating through it." Good navigation makes it easier for users to find the information that they are looking for. When Lizzy was discussing one of her favourite online resources, she stated that she liked "the overall design and the layout, it is very easy to navigate." Whereas poor usability was shown to cause expectant and new mothers difficultly locating required information. Poor usability also negatively impacted their perception of the credibility of the information resource.

Lily was hesitant to purchase products on websites where the features did not function as expected; it made her trust the site less. Susan stopped using an app during the antenatal period because she found it challenging to customise; it was providing her foetal development information on the wrong week. Customisable features are only useful if they are easy for users to engage with.

4.1.5 Perceived utility. Perceived utility is defined in Section 2.2 as " a balance between how useful an information resource is considered and the perceived cost (effort, opportunity cost and monetary cost)." This criterion looked at features that data analysis highlighted as useful, reasons for repeat visits to an information resource. One example of a design feature that a participant found useful is the time function on a baby recipe app, namely the Annabel Karmel app. Susan discussed the value of being able to set a timer for each stage of the recipe.

Guidelines for online information resources

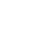


ITP

35,8

\section{8}

Facebook groups were popular amongst the study participants. Maria attributed her use of Facebook groups over forum groups to the integration with her regular newsfeed. She found this useful as it allowed her to build closer connections with members of the group.

My newsfeed would automatically come up, and I would read it, and if anything is of interest to me, I will read through the advice and the information that the other people have given. That's the kind of thing which I find really useful, so I suppose you feel more of a connection than you do with the BabyCentre ones that I used to use before.

\subsection{Information content subjective assessment criteria (ICSAC)}

This section provides an overview of the ICSAC criteria used by expectant and new mothers; this is summarised in Table 6 . The table includes all women whose data were included in the study, and also presented are the ICSAC identified in Section 2.2. An X is used to indicate that there was at least one quote from that participant coded against that criterion. The criteria are organised top-down, with the criteria with the most quotes at the top. The participants are organised left to right, with participants with quotes coded against the broadest range of criteria on the left.

Table 6 illustrates that there were no quotes for the ICSAC criterion accuracy. As a result, there will be no design guidelines based on accuracy in the next section. Unlike the IRSAC, no ICSAC criteria have a quote from every participant. The two ICSAC criteria with the most quotes coded against them are complete and relevance, Table 6 . Relevance is a particularly subjective measure as it refers to how the information meets the needs of the information-seeker. In the following sections, we discuss each of these criteria in more detail.

4.2.1 Security. Security is defined in Section 2.2 as "confidence that the resources will protect user data from misappropriation or unauthorised alteration or loss." The key elements of this criterion are the ability to remain anonymous and keep data private. The criterion was mentioned by only one participant, Susan. Susan felt that pregnancy was an individual experience and appreciated her privacy.

4.2.2 Complete. Complete is defined in Section 2.2 as "the comprehensiveness and depth of the information". The complete criterion can refer to (1) the level of detail provided on a particular topic and (2) the number of different topics per site. BabyCentre was a popular source of information for participants because of the variety of topics available. As stated by Mary, "I knew BabyCentre would have [the information], it holds everything".

We observed a connection between the complete criterion and the credibility criterion. The analysis found that information resources that provided comprehensive information on a topic were often considered more trustworthy. Lizzy decided to opt for a home birth; during the study, she often commented on how much she trusted the midwife who was responsible for her care.

\begin{tabular}{|c|c|c|c|c|c|c|c|c|c|}
\hline Code & Mary & Lizzy & Maria & Janet & Lily & Kelly & Betty & Susan & Celina \\
\hline Complete & $\mathrm{X}$ & $\mathrm{X}$ & $\mathrm{X}$ & $\mathrm{X}$ & $\mathrm{X}$ & $\mathrm{X}$ & & $\mathrm{X}$ & $\mathrm{X}$ \\
\hline Relevance & $\mathrm{X}$ & $\mathrm{X}$ & $\mathrm{X}$ & $\mathrm{X}$ & $\mathrm{X}$ & $\mathrm{X}$ & $\mathrm{X}$ & $\mathrm{X}$ & \\
\hline Currency & & $\mathrm{X}$ & $\mathrm{X}$ & $\mathrm{X}$ & $\mathrm{X}$ & $\mathrm{X}$ & $\mathrm{X}$ & $\mathrm{X}$ & \\
\hline Use of Language & $\mathrm{X}$ & $\mathrm{X}$ & $\mathrm{X}$ & & $\mathrm{X}$ & & $\mathrm{X}$ & & \\
\hline Reliability & $\mathrm{X}$ & & & $\mathrm{X}$ & & $\mathrm{X}$ & & & \\
\hline Concise & & & $\mathrm{X}$ & & & & & & $\mathrm{X}$ \\
\hline Freedom from Bias & $\mathrm{X}$ & $\mathrm{X}$ & & & & & & & \\
\hline References & $\mathrm{X}$ & & & & & & & & \\
\hline Accuracy & & & & & & & & & \\
\hline
\end{tabular}

Table 6.

Summary of information content SAC mentions by participant 
The midwife definitely gives me more information than the hospital ever did. Whether she is for or against she will tell me both and let me decide then. It makes me trust her more, because I know if she is against it, she will still tell me.

Participants often combined multiple information resources to get a full picture. They liked to combine expert resources with personal sources of information. Janet found one online resource, which combined personal stories with expert advice to be particularly useful. She stated that it was difficult to make an informed decision when she did not feel she had all the information. A link was found between the complete criterion and the relevance criterion. If an information resource did not provide enough detail on a topic, it could also be perceived as not being relevant to the user's needs.

The study also found that comprehensive information is not always what is wanted. Susan, Mary, Lizzy and Lily all reported avoiding information at different points. Although Lizzy mostly preferred to have as much information as possible, occasionally she opted to go for a "less is more" strategy. She stated that she would "sometimes just look at basic information and not go into the detail, because it will make [her] worry".

4.2.3 Relevance. Relevance is defined in Section 2.2 as "the applicability of the information to the user's needs." The analysis of the study data found that the relevance of the information was judged primarily based on two factors:

(1) The fit to the task or situation.

(2) The applicability to location

Both Susan and Maria reported that they stopped using information resources because they contained too much irrelevant information. Maria had found the BabyCentre app to be a useful information resource in the antenatal period. However, in the post-natal period, she found it filled with information that did not apply to her.

Participants were not always able to locate information relevant to their specific needs. Maria commented on the vast quantities of information available online but noted that it was still sometimes difficult to find information that precisely fit her requirements.

It is easy to find information; the difficultly is scrolling through to find what is relevant to you. If you put into Google "Placenta Previa" all these different things come up, and you are trying to whittle it down and narrow it down. There is just so much there, and you are trying to tailor it to fit your pregnancy and what you are going through at that time.

Betty stated that she found forums and Facebook more useful in the post-natal period compared with medical sites for specific parenting questions. Betty felt that each child is different, and the medical sites were too general, not allowing for individuality.

I found EuMom brilliant and the Facebook group moms' group, I think teething is very personal, and every child is different. I do not think you can listen to the medical sites because they are telling you every child is the same, and they are not.

Relevance based on location was another issue which came up several times during the study. This varied depending on the information need. Susan, Janet, Mary and Lizzy preferred to access medical information from Irish websites. The difference in healthcare systems partly drove this preference. As a result, UK websites were the second preference because of the similarities between the healthcare system in Ireland and the UK. Location-based relevance was also commented on by Susan when she was looking up weaning guidelines, by Janet when she was looking to purchase a stroller, and by Mary when she was searching for childcare.

4.2.4 Currency. Currency is defined in Section 2.2 as "the age of the information." Analysis of the data found that the currency of information influenced expectant and new mothers'
Guidelines for online information resources 
ITP

35,8

selection of a range of information resources. This criterion was more of a concern during medical information-seeking. The importance of currency for medical information-seeking was driven by the fact that medical information and guidelines are continually being updated and the need to be informed of the latest research.

The majority of participants stated that they preferred to access to up-to-date information. Participants who previously had children were open to reusing their old books for general tasks such as weaning. However, Janet did go online to investigate how guidelines had changed in the interim.

It was found that participants often assumed the position of a search result on Google was a good indicator of the recency of the information. One participant, Maria did not feel a need to check the date of information herself; she just went by the position on Google.

I don't check how old online information is. I suppose I should do really, but I think when you are typing something quite general into Google (maybe I am wrong) that it gives you the newest information first.

Susan was also conscious of the currency of personal resources in the pre-natal period. She felt that people were likely to forget some of the details of what it was like being pregnant. This was particularly true of her mother because it was so long since her mother was pregnant. Interestingly, Susan did not have the same concerns in the post-natal period about parenting advice.

4.2.5 Use of language. Use of language is defined in Section 2.2 as "the information is easy to read and understandable." This is important as it judges if the information content is understandable to the user. This criterion was found to influence the expectant and new mothers' perception of the information resources credibility.

Participants reported finding online health resources such as forums less intimidating than medical professionals, due to the terminology used. The language used by medical professionals can include confusing terminology which may put people off asking questions. Betty reported waiting until she got home from the doctors and either using Google to translate what she had been told or going straight to her mother and baby Facebook group and asking their advice.

I just find the mothers on the Facebook group more down to Earth than the doctors. They will just explain it in a way that you can understand rather than being told things in big medical terms that you have to Google, and you are not sure you heard it right or if you are spelling it right.

Several participants noted differences in the language and tone used in pregnancy and baby websites from different regions. Participants showed preferences for websites that originated from Europe or Australia. Susan felt that some of the American websites were "geared towards the Disneyland pregnancy". Other participants noted that the tone on some American websites felt condescending; the following quote from Maria can illustrate this.

They are American ones, and just the language and the tone they use is kind of condescending I feel anyway. I don't go onto those websites anymore because they just irritate me.

4.2.6 Reliability. In Section 2.2, reliability is defined as "the consistency and dependability of the information". We found that participants did not have any specific methods of judging the reliability of information. However, it was noted that a resources placement within the online search results influenced participants' perception of the information reliability. Mary stated that she usually assumed that on "the first page of results, you get the basic sites that would be a bit more reliable."

Several of the participants liked to return to information resources they had used before. Kelly remarked that she liked to "just go for the same sources because they have been reliable sources for" her. Janet was different, she did not have a reliable source that she liked to go back to instead, she just used Google keyword searches when she needed information. 
4.2.7 Concise. Concise is defined in Section 2.2 as "the information is succinct, lacking in superfluous detail." When information is concise, it enables expectant and new mothers to access relevant information quickly. This criterion is associated with the use of language criterion.

Celina and Maria were particularly interested in concise information. Celina found that once her daughter started moving, she was more distracted and had less time for searching. Celina wanted information that she could quickly read in $10 \mathrm{~min}$. Celina commented that if information were "handed to [her] all neatly on one page [she] would like it but if [she] had five or ten pages to read through probably not." Time restriction was a common issue with participants in the postnatal period and it influenced the frequency of their informationseeking and their choice of information resources.

Maria showed a definite preference for information resources that delivered only the facts. Although she valued her Facebook group, she was dismissive of any other information resource that had "emotive language attached to it".

4.2.8 Freedom from bias. Freedom from bias is defined in Section 2.2 as "the information is not influenced by a particular point of view or agenda." The analysis found that expectant and new mothers were conscious of the views and agendas of authors and the potential bias that advertising could bring to an information resource. This criterion can negatively influence participants' perception of an information resource credibility.

Lizzy avoided information that was sponsored by milk formula companies. She felt that formula companies were influencing certain sites to provide poor breastfeeding advice so women would give up and turn to formula.

I think it has a hidden agenda because it was sponsored by formula companies. They want to make money and they won't make money from mums breastfeeding, so they give out poor advice, so some people supplement with formula.

Participants reported that feeding and weaning were two areas with a lot of conflicting opinions and advice, particularly when it came to Internet forums. Mary reported becoming confused by the conflicting opinions that she found online concerning weaning. This feeling of confusion began to abate when she realised some of the people online were "fanatics of what they believed". Mary and her partner decided to compare the information that they had found to develop a weaning strategy that would work for them.

4.2.9 References. References are defined in Section 2 as "citations for used material or recommendations for additional sources of information." The use of references can increase the credibility of an information resource by highlighting the quality of research.

Although references were only discussed by Mary, it is something that was particularly important to her. Mary commented that a good site was one which "has links to the references where they get their own information from. So, you can then deepen the research more and more yourself."

\section{Design guidelines for online resources for expectant and new mothers}

The objective here was to gain an understanding of how expectant and new mothers process information resources and information content and to use this to generate design guidelines tailored to their needs. The previous section detailed the study's findings and presented the subjective assessment criteria used by participants. This section will present the design guidelines identified based on those findings.

Table 7 presents the design guidelines for online resources for expectant and new mothers. When the analysis was concluded support was found for six of the IRSAC criteria (1) Credibility, (2) Convenience, (3) Format, (4) Usability, (5) Perceived Utility and (6) Security. A seventh criterion was added based on the analysis Rank on Search List. As discussed in the
Guidelines for online information resources 
Design guidelines

Credibility

Convenience

42

Format

Table 7.

Design guidelines for online information resources

List

Usability Security
(1) List background information of contributors including professional qualifications and personal experience

(2) Highlight any professional organisations connected to the eHealth resource

(3) Work to increase brand awareness

(1) Reduce the amount of input required by users of forums

(2) Make site accessible on a wide range of devices

(3) Allow users to change the frequency of push content

(1) Consider the layout, the balance of text and multimedia

(2) Consider using multimedia to enhance users understanding of topics

(3) For general topics, use colours and images to enhance user engagement

Rank on Search (1) Optimise website design to improve search engine rankings

Perceived Utility
(1) Ensure features work properly and function as expected

(2) Ensure online resources are easy to navigate

(1) Allow users to register for notifications for new, relevant content

(1) Facilitate anonymous browsing

previous section, the placement of a resource on the search ranking can influence people's perception of its currency and its reliability. Due to its influence, it was deemed important to include design guidelines specific to this area.

Fourteen design guidelines were created based on the seven IRSAC criteria and are presented in Table 7 . The criteria are ordered in descending order, with the criteria which were discussed most often amongst the participants at the top. As a result, credibility and convenience were the most frequently discussed by participants during the study.

Table 8 presents the design guidelines for online information content for expectant and new mothers. When the analysis was concluded, support was found for eight of the subjective assessment criteria for online resources. However, only seven were used to create design guidelines: (1) Currency, (2) Relevance, (3) Complete, (4) Use of Language, (5) Concise,

\section{Criteria}

Complete

Table 8.

Design guidelines for online information content

Currency

Concise

Bias

\section{Design guidelines}

(1) Topics should be covered in as much detail as possible

(2) Provide a personal folder to allow users to save their own notes, media and links

(3) Provide topic summaries with further detail included in a link or collapsible section

(4) Include a range of topics that interest your target audience

(5) Include a mix of personal stories and expert opinions

Relevance (1) Localise information for different regions

(2) Highlight key points from articles and personal stories

Use of Language

(1) Information should be reviewed and updated regularly

(2) Clearly state the last date information was updated

(1) Be clear and ensure medical terms are explained

(2) Use authoritative language; avoid the use of slang and colloquialisms

(3) Ensure that statistics are used appropriately and explained with a narrative

(1) Summarise facts and avoid extra detail

(2) Provide facts and avoid emotive language

Freedom from

(1) If an article is written from a particular perspective, highlight this

(2) Be conscious of the negative perception that certain sponsors or advertisers could cause

References (1) Clearly display references for source material

(2) Provide references to help users who wish to do additional research on a topic 
(6) Freedom from Bias and (7) References. The last criterion, reliability, was not used for design guidelines because participants only mentioned it was important, they did not articulate how they judged or evaluated it.

Eighteen design guidelines were created based on the seven ICSAC criteria and are presented in Table 8. Like the previous table, the criteria are presented in descending order, with those discussed most often at the top. As a result, complete and relevance were the most frequently discussed by participants during the study.

\section{Conclusion}

The objective of this study was to produce design guidelines for online information resources. These guidelines were presented in the previous section and they emerged based of an analysis of the SAC criteria which were discussed in Section 4. These guidelines have the potential to be utilised as a prescriptive set of recommendations by practitioners (Shneiderman, 2006).

To develop the guidelines, we analysed longitudinal data to understand how the study participants searched for and processed a range of different information resources. By not restricting the analysis to online resources it allowed the researchers to witness why participants sometimes choose between different information resource types and why they sometimes choose to combine them. Focussing solely on online information resources would have prevented us from understanding the assessment criteria used by individuals when multiple information resource types are available (Zhang, 2014). By exploring the criteria used by expectant and new mothers on a range of resources it provided us with richer insights for which to develop the design guidelines for online resources.

Information processing is difficult for researchers to analyse because it is subjective and occurs within the mind of the information-seeker (Wilson, 1997; Bawden and Robinson, 2012). Subjective assessment criteria were used as a lens to understand how participants evaluated and compared a range of different information resources and the information content held within. As information-seekers use subjective judgements when processing information resources, it is important that this is incorporated into the design of information resources (Ho et al., 2013). This should allow the information resource design to reflect the preferences and requirements of the target audience more closely. This method of identifying design guidelines for online information resources could be used in other contexts to create design guidelines specific to those circumstances.

This study built on the information processing model from Mahony et al. (2016), adding subjective assessment criteria as measures for how information content and resources are assessed. Information processing is a crucial part of the information behaviour process, as it plays a role in helping satisfy information needs (Wilson, 1999). However, information processing has remained relatively under-researched, with areas such as information needs and seeking attracting more focus than how information is processed and used (Case and O'Connor, 2016; Pluye et al., 2019).

\subsection{Contributions}

The guidelines can be utilised as a checklist for usability, user experience and design specialists when evaluating online resources for expectant and new mothers. As per Beukes et al. (2016), guidelines can also be used by designers to ensure that they create a product based on the needs of their users and not based on their own opinions.

The guidelines could also be used as a quality measure to test existing online information resources targeted at expectant and new mothers. A large proportion of previous studies which have explored users perception of information quality have focussed on the US and student segments (Ghasemaghaei and Hassanein, 2016). As noted in this study, at least some aspects of these assessments are context specific. Participants in this study, who were based in Ireland, found that American prenatal online resources did not meet their information needs.

Guidelines for online information resources 
ITP

35,8

This research was undertaken from a social constructivist perspective. This means that the design guidelines produced from this research are specific to expectant and new mothers. However, similar to Mason's (2002) discussion on the value of producing cross-sectional generalisation in qualitative research, social constructivists advocate generalisation through testing the applicability of their findings in other contexts (Avenier and Thomas, 2015). As such, we advocate applying the SAC methodology developed and refined during this study to other domains.

Previous studies have highlighted the potential of using the results of information behaviour studies to allow government agencies to understand users better and to create policies and information resources which more closely meet their needs (Xiao et al., 2014). Different stakeholders can have different preferences and different agendas, and guidelines can be a useful way of identifying these and prompting discussion (Yetim, 2006).

\subsection{Limitations and future studies}

This section discusses the limitation of the study and highlights potential directions for future studies. A limitation of the study is the small study size. When conducting research, researchers are faced with many choices, including the choice between breadth and depth. Cross-sectional studies allow researchers to reach theoretical saturation based on the number of participants in their studies. Prospective longitudinal research offers the advantage of depth (c.f. Pettigrew, 1990), and therefore the depth of engagement is how they reach saturation. Testing the guidelines on a larger sample size would offer the opportunity for further refinement which would offer better support for designers and developers.

The study outcome is design guidelines for online resources; the fact that these guidelines were not tested could be perceived as a limitation. However, this can also be an opportunity for a future study. For example, to test these guidelines, an online information resource for expectant and new mothers could be created based on the guidelines. The results could then be tested with this demographic.

Future research should investigate the methodology outlined in the study in other contexts. Future research could use this methodology in other eHealth contexts or expand outside the health domain to other types of users, for example, to explore how remote workers access and process information. This would help to validate the power of its potential across different user groups. During the analysis, connections were noted between the users' perception of the SAC and different antecedents, such as the task type and the time available to search. However, this was not the primary focus of the research and was not investigated further. Conducting a future study into the potential moderating relationship between the antecedents and the user's perception of SAC would provide us with a more comprehensive understanding of how users process information resources (c.f. Ghasemaghaei and Hassanein, 2016). Examining the potential moderating impact of antecedents could result in future refinements to the methodology, which would lead to better design guidelines.

\section{References}

Alzahrani, A.I., Mahmud, I., Ramayah, T., Alfarraj, O. and Alalwan, N. (2017), "Modelling digital library success using the DeLone and McLean information system success model", Journal of Librarianship and Information Science, Vol. 51, pp. 291-306.

Arazy, O. and Kopak, R. (2011), "On the measurability of information quality”, Journal of the American Society for Information Science and Technology, Vol. 62, pp. 89-99.

Athwal, N., Istanbulluoglu, D. and Mccormack Sophie, E. (2019), "The allure of luxury brands' social media activities: a uses and gratifications perspective", Information Technology and People, Vol. 32, pp. 603-626. 
Avenier, M.-J. and Thomas, C. (2015), "Finding one's way around various methodological guidelines for doing rigorous case studies: a comparison of four epistemological frameworks", Systèmes D'Information et Management, Vol. 20, pp. 61-98.

Bailey, J.E. and Pearson, S.W. (1983), "Development of a tool for measuring and analyzing computer user satisfaction”, Management Science, Vol. 29, pp. 530-545.

Barkin, J.L., Wisner, K.L., Bromberger, J.T., Beach, S.R. and Wisniewski, S.R. (2010), "Assessment of functioning in new mothers", Journal of Women's Health, Vol. 19, pp. 1493-1499.

Bawden, D. and Robinson, L. (2012), An Introduction to Information Science, Facet Publishing, London.

Beldad, A., De Jong, M. and Steehouder, M. (2011), "A comprehensive theoretical framework for personal information-related behaviors on the internet", The Information Society, Vol. 27, pp. 220-232.

Benbasat, I., Goldstein, D.K. and Mead, M. (1987), "The case research strategy in studies of information systems", MIS Quarterly, Vol. 11, pp. 369-386.

Bernhardt, J.M. and Felter, E.M. (2004), "Online pediatric information seeking among mothers of young children: results from a qualitative study using focus groups", Journal of Medical Internet Research, Vol. 6, p. e7.

Beukes, W., Gelderblom, H. and Van Der Merwe, A., (2016), Why designers responsible for websites of large organisations disregard basic web design principles, International Conference on Information Resources Management (CONF-IRM), Association for Information Systems AIS Electronic Library (AISeL).

Blankenburg Holm, D., Drogendijk, R. and Haq, H.U. (2020), “An attention-based view on managing information processing channels in organizations", Scandinavian Journal of Management, Vol. 36, p. 101106.

Brady, E. and Guerin, S. (2010), “Not the romantic, all happy, coochy coo experience': a qualitative analysis of interactions on an Irish parenting web site", Family Relations, Vol. 59, pp. 14-27.

Braun, V. and Clarke, V. (2006), "Using thematic analysis in psychology", Qualitative Research in Psychology, Vol. 3, pp. 77-101.

Case, D.O. and O'connor, L.G. (2016), "What's the use? Measuring the frequency of studies of information outcomes", Journal of the Association for Information Science and Technology, Vol. 67, pp. 649-661.

Cheung, C.M.K., Lee, M.K.O. and Rabjohn, N. (2008), "The impact of electronic word-of-mouth: the adoption of online opinions in online customer communities", Internet Research, Vol. 18, pp. 229-247.

Cline, R.J. and Haynes, K.M. (2001), "Consumer health information seeking on the internet: the state of the art", Health Education Research, Vol. 16, pp. 671-692.

Cohen, J.H. and Raymond, J.M. (2011), "How the internet is giving birth (to) a new social order", Information, Communication and Society, Vol. 14, pp. 937-957.

Corti, L. (1993), Using Diaries in Social Research [Online], Department of Sociology: University of Surrey, available at: http://sru.soc.surrey.ac.uk/SRU2.html (accessed 10 August 2016).

Courtright, C. (2007), "Context in information behavior research", Annual Review of Information Science and Technology, Vol. 41, pp. 273-306.

Creswell, J.W. and Miller, D.L. (2000), "Determining validity in qualitative inquiry”, Theory Into Practice, Vol. 39, pp. 124-130.

Das, A. and Sarkar, M. (2014), "Pregnancy-related health information-seeking behaviors among rural pregnant women in India: validating the Wilson model in the Indian context", The Yale Journal of Biology and Medicine, Vol. 87, pp. 251-262.

Davis, K.E. (2015), The Information Experience of New Mothers in Social Media: A Grounded Theory Study, PhD Thesis, Queensland University of Technology.

Guidelines for online information resources 
ITP

35,8
Delone, W.H. and Mclean, E.R. (1992), "Information systems success: the quest for the dependent variable", Information Systems Research, Vol. 3, pp. 60-95.

Delone, W.H. and Mclean, E.R. (2003), "The DeLone and McLean model of information systems success: a ten-year update”, Journal of Management Information Systems, Vol. 19, pp. 9-30.

Deng, M., Liu, H., Ding, G. and Huang, Q. (2017), "Effects of ESM usage on job performance through task structure: the moderating role of team diversity", Thirty Eighth International Conference on Information Systems (ICIS), Seoul.

Dicicco-Bloom, B. and Crabtree, B.F. (2006), “The qualitative research interview”, Medical Education, Vol. 40, pp. 314-321.

Doll, W.J. and Torkzadeh, G. (1988), "The measurement of end-user computing satisfaction", MIS Quarterly, Vol. 12, pp. 259-274.

Eisenhardt, K.M. and Graebner, M.E. (2007), "Theory building from cases: opportunities and challenges”, Academy of Management Journal, Vol. 50, pp. 25-32.

Ek, S. (2015), "Gender differences in health information behaviour: a Finnish population-based survey", Health Promotion International, Vol. 30, pp. 736-745.

Ellis, D., Cox, D. and Hall, K. (1993), "A comparison of the information seeking patterns of researchers in the physical and social sciences", Journal of Documentation, Vol. 49, pp. 356-369.

Ellis, D., Allen, D. and Wilson, T.D. (1999), "Information science and information systems: conjunct subjects disjunct disciplines", Journal of the Association for Information Science and Technology, Vol. 50, p. 1095.

Fisher, K.E. and Julien, H. (2009), "Information behavior", Annual Review of Information Science and Technology, Vol. 43, pp. 1-73.

Foster, A. (2004), "A nonlinear model of information-seeking behavior", Journal of the American Society for Information Science and Technology, Vol. 55, pp. 228-237.

Fourney, A., White, R.W. and Horvitz, E. (2015), "Exploring time-dependent concerns about pregnancy and childbirth from search logs", Conference on Human Factors in Computing Systems - Proceedings, pp. 737-746.

Gable, G.G., Sedera, D. and Chan, T. (2008), "Re-conceptualizing information system success: the ISimpact measurement model", Journal of the Association for Information Systems, Vol. 9, pp. 377-408.

Gao, L.-L., Larsson, M. and Luo, S.-Y. (2013), "Internet use by Chinese women seeking pregnancyrelated information", Midwifery, Vol. 29, pp. 730-735.

Gao, L., Waechter, K.A. and Bai, X. (2015), "Understanding consumers' continuance intention towards mobile purchase: a theoretical framework and empirical study - a case of China", Computers in Human Behavior, Vol. 53, pp. 249-262.

Ghasemaghaei, M. and Hassanein, K. (2015), "Online information quality and consumer satisfaction: the moderating roles of contextual factors - a meta-analysis", Information and Management, Vol. 52, pp. 965-981.

Ghasemaghaei, M. and Hassanein, K. (2016), "A macro model of online information quality perceptions: a review and synthesis of the literature", Computers in Human Behavior, Vol. 55, pp. 972-991.

Gibson, L. and Hanson, V.L. (2013), "Digital motherhood: how does technology help new mothers?”, Proceedings of the SIGCHI Conference on Human Factors in Computing Systems, April 27 May 2, 2013, Paris, ACM, pp. 313-322, 2470700.

Gorla, N., Somers, T.M. and Wong, B. (2010), "Organizational impact of system quality, information quality, and service quality", The Journal of Strategic Information Systems, Vol. 19, pp. 207-228.

Hair, J.F. (2007), Research Methods for Business, John Wiley \& Sons. 
Hilligoss, B. and Rieh, S.Y. (2008), "Developing a unifying framework of credibility assessment: construct, heuristics, and interaction in context", Information Processing and Management, Vol. 44, pp. 1467-1484.

Ho, S.M., Bieber, M., Song, M. and Zhang, X. (2013), "Seeking beyond with IntegraL: a user study of sense-making enabled by anchor-based virtual integration of library systems", Journal of the American Society for Information Science and Technology, Vol. 64, pp. 1927-1945.

Hsu, M.-H., Chang, C.-M., Chu, K.-K. and Lee, Y.J. (2014), "Determinants of repurchase intention in online group-buying: the perspectives of DeLone \& McLean IS success model and trust", Computers in Human Behavior, Vol. 36, pp. 234-245.

Hughes, H. (2006), "Responses and influences: a model of online information use for learning", Information Research, Vol. 12, p. 279, available at: http://InformationR.net/ir/12-1/paper279.html.

Hwang, Y., Kettinger, W.J. and Yi, M. (2010), "Understanding information behavior and the relationship to job performance", Communications of the Association for Information Systems, Vol. 27, p. 8.

Ikhalia, E., Serrano, A., Bell, D. and Louvieris, P. (2019), "Online social network security awareness: mass interpersonal persuasion using a Facebook app", Information Technology and People, Vol. 32, pp. 1276-1300.

Introne, J., Erickson, I., Semaan, B. and Goggins, S. (2019), "Designing sustainable online support: examining the effects of design change in 49 online health support communities", Journal of the Association for Information Science and Technology, Vol. 71 No. 4, pp. 379-394.

Jeyaraj, A. (2020), "DeLone \& McLean models of information system success: critical meta-review and research directions", International Journal of Information Management, Vol. 54, p. 102139.

Kari, T., Salo, M. and Frank, L. (2020), "Role of situational context in use continuance after critical exergaming incidents", Information Systems Journal, Vol. 30, pp. 596-633.

Kim, C., Lee, I.-S., Wang, T. and Mirusmonov, M. (2015), "Evaluating effects of mobile CRM on employees' performance”, Industrial Management and Data Systems, Vol. 115, pp. 740-764.

Klein, H.K. and Myers, M.D. (1999), "A set of principles for conducting and evaluating interpretive field studies in information systems", MIS Quarterly, Vol. 23, pp. 67-93.

Lagan, B.M., Sinclair, M. and Kernohan, W.G. (2010), "Internet use in pregnancy informs women 's decision making : a web-based survey", Journal of Medical Internet Research, Vol. 37, pp. 106-115.

Larsson, M. (2009), "A descriptive study of the use of the internet by women seeking pregnancyrelated information", Midwifery, Vol. 25, pp. 14-20.

Latour, B. (1990), "Technology is society made durable", The Sociological Review, Vol. 38, pp. 103-131.

Lee, A.S. (1989), “A scientific methodology for MIS case studies”, MIS Quarterly, Vol. 13, pp. 33-50.

Lee, H.S. (2018), "A comparative study on the health information needs, seeking and source preferences among mothers of young healthy children: American mothers compared to recent immigrant Korean mothers", Information Research, Vol. 23.

Lee, C.K.H., Tse, Y.K., Zhang, M. and Ma, J. (2019a), “Analysing online reviews to investigate customer behaviour in the sharing economy: the case of Airbnb", Information Technology and People.

Lee, J.Y.-H., Yang, C.-S., Hsu, C. and Wang, J.-H. (2019b), "A longitudinal study of leader influence in sustaining an online community", Information and Management, Vol. 56, pp. 306-316.

Lee, T., Lee-Geiller, S. and Lee, B.-K. (2020), "Are pictures worth a thousand words? The effect of information presentation type on citizen perceptions of government websites", Government Information Quarterly, Vol. 37, p. 101482.

Leeder, C. (2019), "How college students evaluate and share "fake news" stories", Library and Information Science Research, Vol. 41, p. 100967.

Liang, H., Xue, Y. and Zhang, Z. (2017), "Understanding online health information use: the case of people with physical disabilities", Journal of the Association for Information Systems, Vol. 18, pp. $433-460$. 
ITP

35,8

Madge, C. and O'connor, H. (2006), "Parenting gone wired: empowerment of new mothers on the internet?", Social and Cultural Geography, Vol. 7, pp. 199-220.

Mahony, C., Sammon, D. and Heavin, C. (2016), "Design guidelines for online resources: a longitudinal analysis of information processing", Proceedings of the IFIP WG 8.3 Conference: Big Data, Better, Cork, Taylor \& Francis.

Mahony, C., Heavin, C. and Sammon, D. (2021), "Health-related information resource use: an exploratory study of expectant mothers", Journal of Decision Systems, pp. 1-24.

Mason, J. (2002), Qualitative Researching, The Cromwell Press, Sage, Wiltshire.

Mckenzie, P.J. (2004), "Positioning theory and the negotiation of information needs in a clinical midwifery setting", Journal of the American Society for Information Science and Technology, Vol. 55, pp. 685-694.

Mckinney, V., Yoon, K. and Zahedi, F.M. (2002), "The measurement of web-customer satisfaction: an expectation and disconfirmation approach", Information Systems Research, Vol. 13, pp. 296-315.

Meppelink, C.S., Smit, E.G., Diviani, N. and Van Weert, J.C.M. (2016), "Health literacy and online health information processing: unraveling the underlying mechanisms", Journal of Health Communication, Vol. 21, pp. 109-120.

Metzger, M.J. (2007), "Making sense of credibility on the Web: models for evaluating online information and recommendations for future research", Journal of the American Society for Information Science and Technology, Vol. 58, pp. 2078-2091.

Miles, M.B., Huberman, A.M. and Saldaña, J. (2013), Qualitative Data Analysis: A Methods Sourcebook, Sage Publications, Thousand Oaks, CA.

Montesi, M. (2017), "Defining a theoretical framework for information seeking and parenting: concepts and themes from a study with mothers supportive of attachment parenting", Journal of Documentation, Vol. 73, pp. 186-209.

Myers, M.D. and Newman, M. (2007), "The qualitative interview in IS research: examining the craft", Information and Organization, Vol. 17, pp. 2-26.

Naveh, S. and Bronstein, J. (2019), "Sense making in complex health situations: virtual health communities as sources of information and emotional support", Aslib Journal of Information Management, Vol. 71, pp. 789-805.

Ngwenyama, O. and Nielsen, P.A. (2014), "Using organizational influence processes to overcome IS implementation barriers: lessons from a longitudinal case study of SPI implementation", European Journal of Information Systems, Vol. 23, pp. 205-222.

O'connor, H. and Madge, C. (2004), "My mum's thirty years out of date' the role of the Internet in the transition to motherhood", Community, Work and Family, Vol. 7, pp. 351-369.

Orlikowski, W.J. and Baroudi, J.J. (1991), "Studying information technology in organizations: research approaches and assumptions", Information Systems Research, Vol. 2, pp. 1-28.

Park, M. (2013). Multi-dimensional analysis of dynamic human information interaction, Information Research, Vol. 18, p. 566.

Petter, S., Delone, W. and Mclean, E.R. (2013), "Information systems success: the quest for the independent variables", Journal of Management Information Systems, Vol. 29, pp. 7-62.

Pettigrew, A.M. (1990), "Longitudinal field research on change: theory and practice", Organization Science, Vol. 1, pp. 267-292.

Pettigrew, S., Archer, C. and Harrigan, P. (2016), "A thematic analysis of mothers' motivations for blogging", Maternal and Child Health Journal, Vol. 20, pp. 1025-1031.

Plantin, L. and Daneback, K. (2009), "Parenthood, information and support on the internet. A literature review of research on parents and professionals online", BMC Family Practice, Vol. 10, p. 34.

Ployhart, R.E. and Vandenberg, R.J. (2010), "Longitudinal research: the theory, design, and analysis of change”, Journal of Management, Vol. 36, pp. 94-120. 
Pluye, P., EL Sherif, R., Granikov, V., Hong, Q.N., Vedel, I., Galvao, M.C.B., Frati, F.E.Y., Desroches, S., Repchinsky, C., Rihoux, B., Légaré, F., Burnand, B., Bujold, M. and Grad, R. (2019), "Health outcomes of online consumer health information: a systematic mixed studies review with framework synthesis", Journal of the Association for Information Science and Technology, Vol. 70, pp. 643-659.

Porter, N. and Ispa, J.M. (2013), “Mothers' online message board questions about parenting infants and toddlers", Journal of Advanced Nursing, Vol. 69, pp. 559-568.

Prescott, J. and Mackie, L. (2017), "You sort of go down a rabbit Hole. . .You 're just going to keep on searching': a qualitative study of searching online for pregnancy-related information during pregnancy", Journal of Medical Internet Research, Vol. 19, p. e194.

Qu, S.Q. and Dumay, J. (2011), “The qualitative research interview”, Qualitative Research in Accounting and Management, Vol. 8, pp. 238-264.

Rieh, S.Y. (2002), "Judgment of information quality and cognitive authority in the web", Journal of the American Society for Information Science and Technology, Vol. 53, pp. 145-161.

Rieh, S.Y. and Danielson, D.R. (2007), "Credibility: a multidisciplinary framework”, Annual Review of Information Science and Technology, Vol. 41, pp. 307-364.

Rodríguez-Ardura, I. and Meseguer-Artola, A. (2019), "Imagine, feel 'there', and flow! Immersive experiences on m-Facebook, and their affective and behavioural effects", Information Technology and People, Vol. 32, pp. 921-947.

Ruthven, I., Buchanan, S. and Jardine, C. (2018), "Isolated, overwhelmed, and worried: young first-time mothers asking for information and support online", Journal of the Association for Information Science and Technology, Vol. 69, pp. 1073-1083.

Sanders, R., Linn, A.J., Araujo, T.B., Vliegenthart, R., Van Eenbergen, M.C. and Van Weert, J.C.M. (2020), "Different platforms for different patients' needs: automatic content analysis of different online health information platforms", International Journal of Human-Computer Studies, Vol. 137, p. 102386.

Sarkar, J.G. and Sarkar, A. (2019), "Young adult consumers' involvement in branded smartphone based service apps: investigating the roles of relevant moderators", Information Technology and People, Vol. 32, pp. 1608-1632.

Savolainen, R. (2011), "Judging the quality and credibility of information in Internet discussion forums", Journal of the American Society for Information Science and Technology, Vol. 62, pp. 1243-1256.

Sawyer, S. and Huang, H. (2007), "Conceptualizing information, technology, and people: comparing information science and information systems literatures", Journal of the American Society for Information Science and Technology, Vol. 58, pp. 1436-1447.

Sbaffi, L. and Rowley, J. (2017), "Trust and credibility in web-based health information: a review and agenda for future research", Journal of Medical Internet Research, Vol. 19, p. e218.

Shieh, C., Mcdaniel, A. and Ke, I. (2009), "Information-seeking and its predictors in low-income pregnant women", Journal of Midwifery and Women's Health, Vol. 54, pp. 364-372.

Shneiderman, B. (2006), "Foreword", in Based Web Design \& Usability Guidelines, Health and Human Services Department.

Sillence, E., Briggs, P., Harris, P. and Fishwick, L. (2007a), "Going online for health advice: changes in usage and trust practices over the last five years", Interacting with Computers, Vol. 19, pp. 397-406.

Sillence, E., Briggs, P., Harris, P. and Fishwick, L. (2007b), "How do patients evaluate and make use of online health information?", Social Science and Medicine, Vol. 64, pp. 1853-62.

Slomian, J., Bruyère, O., Reginster, J.Y. and Emonts, P. (2017), "The internet as a source of information used by women after childbirth to meet their need for information: a web-based survey", Midwifery, Vol. 48, pp. 46-52. 
ITP

35,8

Soroya, S.H., Farooq, A., Mahmood, K., Isoaho, J. and Zara, S.-E. (2021), "From information seeking to information avoidance: understanding the health information behavior during a global health crisis", Information Processing and Management, Vol. 58, p. 102440.

Straub, D., Boudreau, M. and Gefen, D. (2004), "Validation guidelines for IS positivist research", Communications of the Association for Information Systems, Vol. 13, doi: 10.17705/ 1CAIS.01324.

Strong, D.M., Lee, Y.W. and Wang, R.Y. (1997), "Data quality in context", Communications of the ACM, Vol. 40, pp. 103-110.

Sun, Y., Zhang, Y., Gwizdka, J. and Trace, C.B. (2019), "Consumer evaluation of the quality of online health information: systematic literature review of relevant criteria and indicators", Journal of Medical Internet Research, Vol. 21, p. e12522.

Walsham, G. (1995), "Interpretive case studies in IS research: nature and method", European Journal of Information Systems, Vol. 4, pp. 74-81.

Wang, Y.-S. (2008), "Assessing E-commerce systems success: a respecification and validation of the DeLone and McLean model of IS success”, Information Systems Journal, Vol. 18, pp. 529-557.

Watson, C. (2014), "An exploratory study of secondary students' judgments of the relevance and reliability of information", Journal of the Association for Information Science and Technology, Vol. 65, pp. 1385-1408.

Webster, J. and Watson, R.T. (2002), “Analyzing the past to prepare for the future: writing a literature review”, MIS Quarterly, Vol. 26, pp. xiii-xxiii.

Wennberg, A.L., Lundqvist, A., Högberg, U., Sandström, H. and Hamberg, K. (2013), "Women's experiences of dietary advice and dietary changes during pregnancy", Midwifery, Vol. 29, pp. 1027-1034.

Wilson, T.D. (1981), “On user studies and information needs", Journal of Documentation, Vol. 37, pp. 3-15.

Wilson, P. (1983), Second-hand Knowledge: An Inquiry into Cognitive Authority, The University of Michigan, Greenwood Press.

Wilson, T.D. (1997), "Information behaviour: an interdisciplinary perspective", Information Processing and Management, Vol. 33, pp. 551-572.

Wilson, T.D. (1999), "Models in information behaviour research", Journal of Documentation, Vol. 55, pp. $249-270$.

Wilson, T.D. (2000), "Human information behavior", Informing Science, Vol. 3, pp. 49-56.

Wixom, B.H. and Todd, P.A. (2005), "A theoretical integration of user satisfaction and technology acceptance”, Information Systems Research, Vol. 16, pp. 85-102.

Wood, W., Kallgren, C.A. and Preisler, R.M. (1985), "Access to attitude-relevant information in memory as a determinant of persuasion: the role of message attributes", Journal of Experimental Social Psychology, Vol. 21, pp. 73-85.

Xiao, N., Sharman, R., Rao, H.R. and Upadhyaya, S. (2014), "Factors influencing online health information search: an empirical analysis of a national cancer-related survey", Decision Support Systems, Vol. 57, pp. 417-427.

Xiong, J. and Zuo, M. (2019), "How does family support work when older adults obtain information from mobile internet?", Information Technology and People, Vol. 32, pp. 1496-1516.

Yadav, D., Malik, P., Dabas, K. and Singh, P. (2019), "FeedPal: understanding opportunities for chatbots in breastfeeding education of women in India", Proceedings of the ACM on HumanComputer Interaction, Vol. 3.

Yang, Z., Cai, S., Zhou, Z. and Zhou, N. (2005), "Development and validation of an instrument to measure user perceived service quality of information presenting web portals", Information and Management, Vol. 42, pp. 575-589. 
Yetim, F. (2006), "Bridging diversity: a deliberative approach to organizing and application of usability guidelines", European Conference on Information Systems (ECIS), Göteborg, Sweden, p. 182.

Zaphiris, P., Pfeil, U. and Xhixho, D. (2009), "User evaluation of age-centred web design guidelines", UAHCI 2009: Universal Access in Human-Computer Interaction. Addressing Diversity, Berlin, Springer Berlin Heidelberg, pp. 677-686.

Zhang, Y. (2014), "Beyond quality and accessibility: source selection in consumer health information searching", Journal of the Association for Information Science and Technology, Vol. 65, pp. 911-927.

Zhang, J., Luo, B. and Cao, F. (2019), "The antecedent and consequence of users' satisfaction and dissatisfaction with information seeking in online health communities", Proceedings of the Association for Information Science and Technology, Vol. 56, pp. 836-837.

Zhang, Y., Li, X. and Fan, W. (2020), "User adoption of physician's replies in an online health community: an empirical study", Journal of the Association for Information Science and Technology, Vol. 71, pp. 1179-1191.

Zheng, Y., Zhao, K. and Stylianou, A. (2013), "The impacts of information quality and system quality on users' continuance intention in information-exchange virtual communities: an empirical investigation”, Decision Support Systems, Vol. 56, pp. 513-524.

\section{Corresponding author}

Carolanne Mahony can be contacted at: carolanne.mahony@ucc.ie
Guidelines for online information resources

For instructions on how to order reprints of this article, please visit our website: 